\title{
Reciprocating Wear Behavior of Ni-Co Alloys Produced by Pulse Current Electrodeposition
}

\author{
R. KarslioĞLu*, M. Uysal, A. Alp and H. Akbulut \\ Sakarya University Engineering Faculty, Department of Metallurgical and Materials Engineering \\ Esentepe Campus, 54187, Sakarya, Turkey
}

\begin{abstract}
In the present work, Ni-Co alloy coatings were prepared from a modified Watt type electrolyte by direct current. For this purpose, current density was investigated for optimization to obtain high quality coatings on the steel copper substrates. The depositions were controlled to obtain specific thickness (between 50 and $200 \mu \mathrm{m}$ ). The characterization of the coatings was investigated by scanning electron microscopy and X-ray diffraction facilities. The hardness of the resultant coatings was also measured. The effects of the current density on the tribological properties of $\mathrm{Ni}-\mathrm{Co}$ coatings were investigated. The results showed that although increasing current density showed increasing coating thickness, the wear resistance of the Ni-Co alloys was decreased due to Co depletion in the deposited layer.
\end{abstract}

DOI: 10.12693/APhysPolA.123.424

PACS: 68.35.bd, 82.45.Aa

\section{Introduction}

$\mathrm{Ni}-\mathrm{Co}$ alloy coatings have been widely used as recording head materials in computer hard drive industries. The thickness of the magnetic layer used in the microelectrical mechanical system (MEMS) can vary from a few nanometers to a few millimeters, depending on the applications, and the magnetic thin films must have good adhesion and corrosion resistance and low-stress, and be thermally stable with excellent magnetic properties [1]. Several studies reported that the magnetic properties of $\mathrm{Ni}-\mathrm{Co}$ alloy was greatly influenced by the composition and phase structure of $\mathrm{Ni}-\mathrm{Co}$ alloy. Unfortunately, there are very limited studies focused on the friction and wear properties of $\mathrm{Ni}-\mathrm{Co}$ alloys as a function of their microstructure and composition [2-5], it is essential and feasible to improve the comprehensive properties of $\mathrm{Ni}-\mathrm{Co}$ alloy applying pulse current and altering current density.

\section{Experimental}

The plating electrolyte for the electrodeposition of $\mathrm{Ni}-\mathrm{Co}$ alloys were a Watt-type bath. Figure 1 shows a pulse current source and a schematic representation of the electrodeposition system. The basic composition of the electrolyte and the plating conditions are also shown in Fig. 1. The temperature of the electrolyte during deposition of alloy was controlled at $45^{\circ} \mathrm{C}( \pm 2)$ and the $\mathrm{pH}$ was fixed at $4( \pm 0.2)$.

In the electrodeposition experiments, three different pulse currents were studied to obtain optimum conditions for homogeneous microstructures. Plating time was $120 \mathrm{~min}$ for each electroplating run. The process steps

*corresponding author; e-mail: rkarslioglu@sakarya.edu.tr

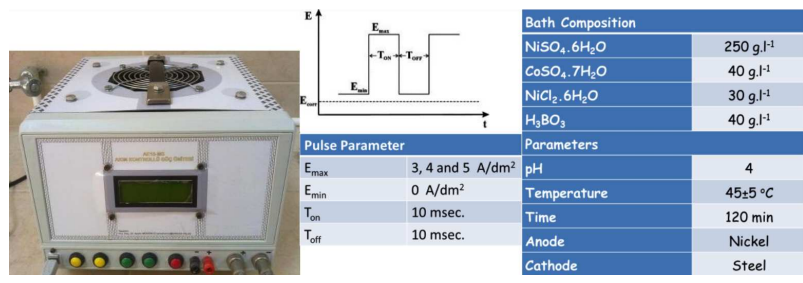

Fig. 1. Pulse power supplier, pulse parameter and coating conditions.

are: (i) polishing of substrate, (ii) preparation of electrolyte, (iii) magnetic stirring for $30 \mathrm{~min}$, (iv) performing electrodeposition for $120 \mathrm{~min}$.

Microstructural investigations were performed by JEOL-JSM 6060LV SEM instrument. The hardness of the coatings was measured by using a Vickers microhardness indenter (Leica VMHT) with a load of $50 \mathrm{~g}$. Wear and friction tests were performed with a reciprocating ball-on disk CSM tribometer at room temperature with a relative humidity of $55-65 \%$ under dry sliding conditions. Counterpart was $\mathrm{Al}_{2} \mathrm{O}_{3}$ ball $(\varnothing 10 \mathrm{~mm})$. The system allows measuring friction coefficient by using sensitive transducers. Thus, the tests were performed at a constant applied load of $1.0 \mathrm{~N}$ with a sliding speed of $0.05 \mathrm{~m} / \mathrm{s}$.

\section{Results and discussion}

In the electrodeposition process, it was aimed to produce a layer of the $\mathrm{Ni}-\mathrm{Co}$ alloy. Figure 2 shows the microstructure of the alloys that was produced by using different current applications. The microstructures show that all alloys coating steel substrates by electrodeposition show uniform grain size and shape.

In Fig. 3 energy dispersive spectroscopy (EDS) and $\mathrm{X}$-ray diffraction (XRD) analysis results are given for the 


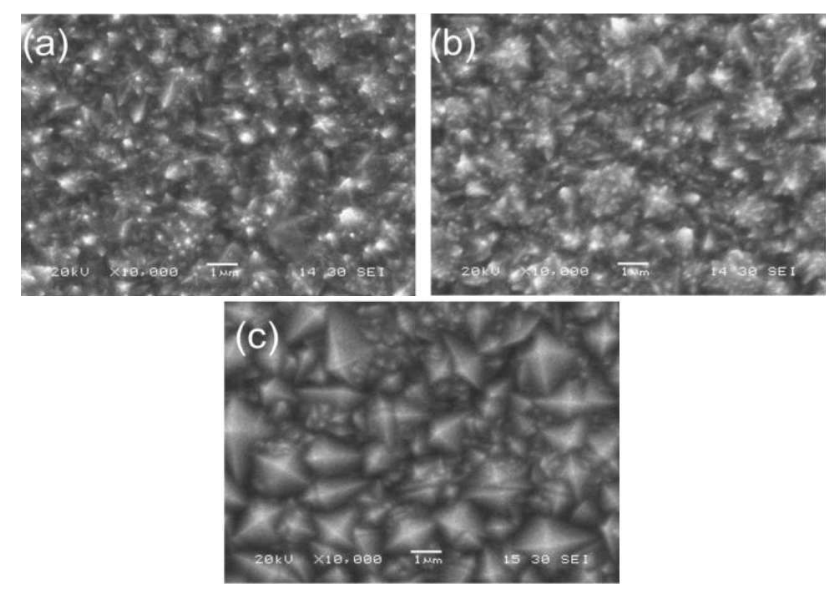

Fig. 2. High magnification surface structure of electrodeposited Ni-Co coatings: (a) $3.0 \mathrm{~A} / \mathrm{dm}^{2}$, (b) $4.0 \mathrm{~A} / \mathrm{dm}^{2}$, (c) $5.0 \mathrm{~A} / \mathrm{dm}^{2}$.

coating obtained at $3.0 \mathrm{~A} / \mathrm{dm}^{2}$. XRD analysis gives preferential analysis growth in two distinct planes of $(\alpha 111)$ and $(\alpha 220)$ with increasing applied current $\left(E_{\max }\right)$.

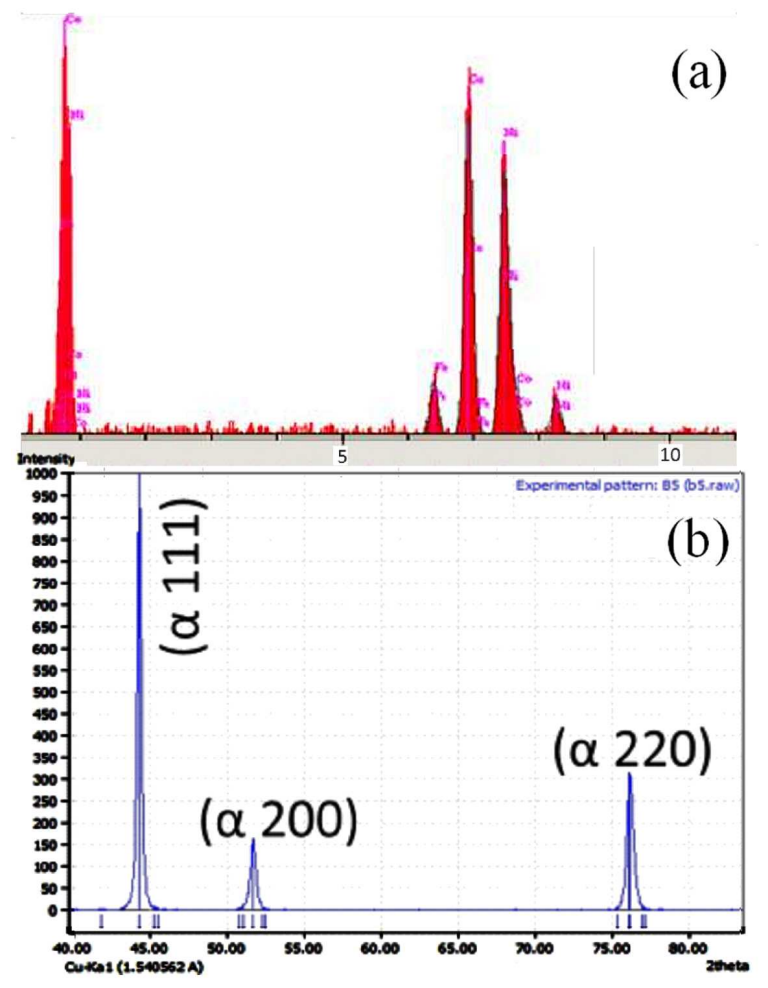

Fig. 3. EDS (a) and XRD (b) analysis of electrodeposited Ni-Co coating at $3.0 \mathrm{~A} / \mathrm{dm}^{2}$.

The microhardness measurement results are shown in Fig. 4. Microhardness tests confirmed that the hardness of alloys coatings depends on the applied current. The hardness of the alloys decreases with increasing applied current $E_{\max }$.

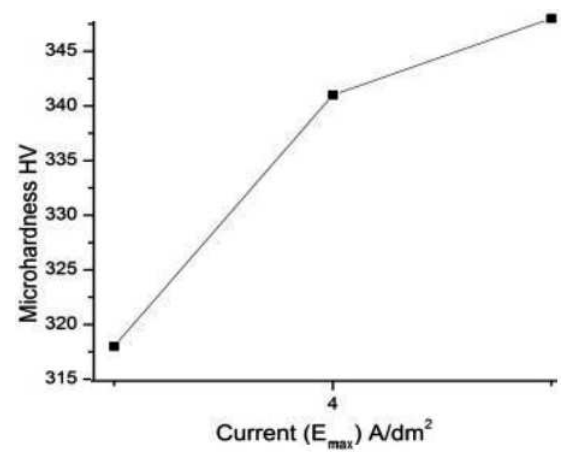

Fig. 4. Microhardness of Ni-Co layer.

When Fig. 5 is seen, it can be observed that in the alloys, a mixed mode of adhesive-abrasive wear occurred for all the conditions. From the low magnification scanning electron microscopy (SEM) micrographs, it can easily be seen that wear tracks to show the highest wear appeared in the sample that was produced at $E_{\max }=$ $3.0 \mathrm{~A} / \mathrm{dm}^{2}$ current. For under $3.0 \mathrm{~A} / \mathrm{dm}^{2}$ coating the wear track shows identical mechanism, while the sample produced under $4.0 \mathrm{~A} / \mathrm{dm}^{2}$ exhibits a typical adhesive wear and severe delamination along the sliding direction under the combined stresses of compression and shear. In Fig. 5, heavy plastic deformation is seen with increasing current during deposition. Mainly, the plastic deformation occurs by smearing of the wear debris on the coatings.

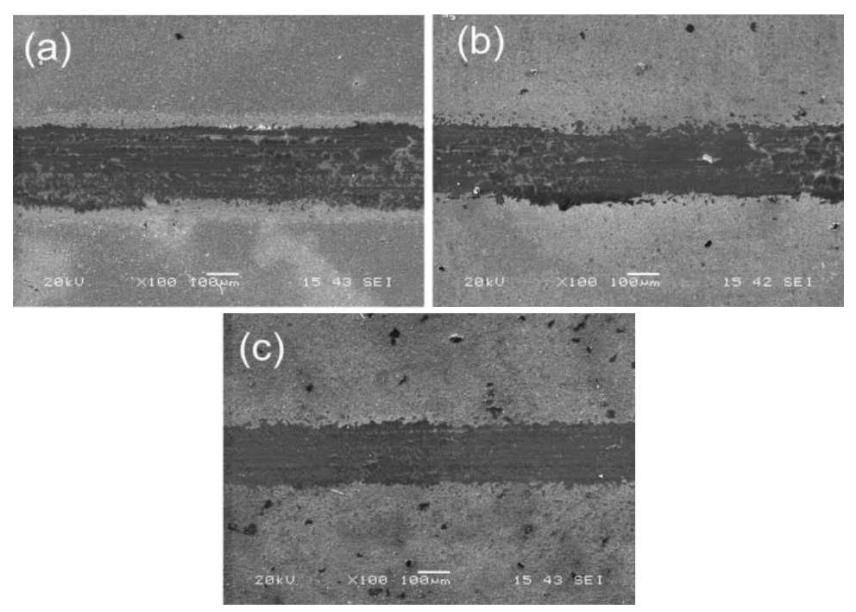

Fig. 5. Low magnification wear tracks of electrodeposited Ni-Co: (a) $3.0 \mathrm{~A} / \mathrm{dm}^{2}$, (b) $4.0 \mathrm{~A} / \mathrm{dm}^{2}$, and (c) $5.0 \mathrm{~A} / \mathrm{dm}^{2}$.

Figure 6 shows the wear rate and friction coefficient values of the alloy that were produced with $E_{\max } 5.0$ $\mathrm{A} / \mathrm{dm}^{2}$ are the lowest among studied coatings. This is because this current is the optimum value and resulted in decreasing grain size and hardness to provide high wear resistance. Therefore, wear rate and friction coefficient decreases with increasing $E_{\max }$. 


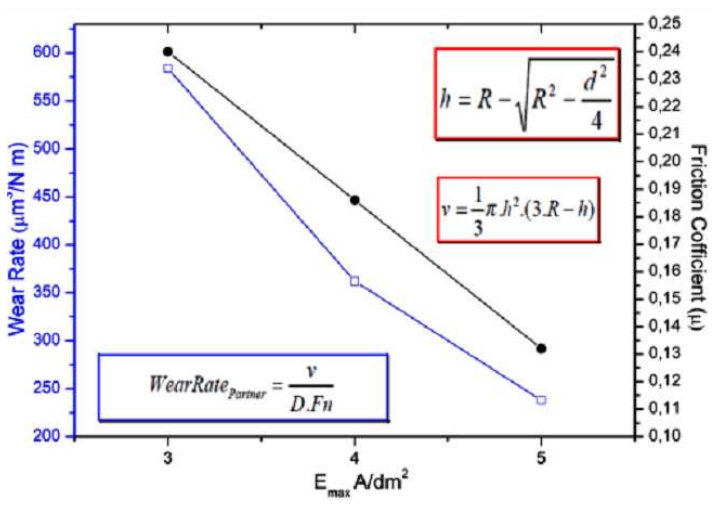

Fig. 6. Effect of current on wear rate and friction coefficient of coatings.
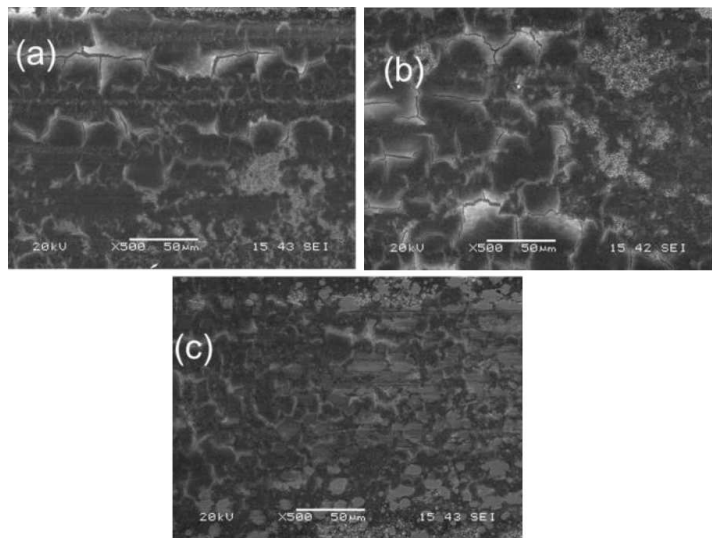

Fig. 7. High magnification worn surfaces of electrodeposited Ni-Co alloys: (a) $3.0 \mathrm{~A} / \mathrm{dm}^{2}$, (b) $4.0 \mathrm{~A} / \mathrm{dm}^{2}$, and (c) $5.0 \mathrm{~A} / \mathrm{dm}^{2}$.

Figure 7 shows four typical SEM morphologies of worn surfaces of the Ni-Co alloys produced with different current densities. Figure $7 \mathrm{a}$ shows the worn surface of the $\mathrm{Ni}-\mathrm{Co}$ deposited layer produced with $E_{\max } 5 \mathrm{~A} / \mathrm{dm}^{2}$ cur- rent. As can be seen in Fig. 7a Ni-Co alloy shows an extensive amount of plastic deformation is occurred. Plastic deformation is seen to cause smearing of the wear debris on the sliding surface coming from the electrodeposited alloy and then plastic deformation occurs when sliding continues. The cracks are evidence that after deformation hardening, delamination type of the material transfer will occur when the current density is increased.

\section{Conclusions}

1. The Ni-Co layer has been successfully synthesized by a pulse electrodeposition process.

2. All the Ni-Co coatings on copper substrates produced by electrodeposition show uniform distribution of grain size and shape.

3. EDS analysis shows $\mathrm{Co}$ ratio in the $\mathrm{Ni}-\mathrm{Co}$ layer decreases with increasing current density $\left(E_{\max }\right)$.

4. XRD analysis shows preferential $\mathrm{Ni}-\mathrm{Co}$ growth in two distinct planes of $(\alpha 111)$ and $(\alpha 220)$ with increasing $E_{\max }$.

5. Wear rate and friction coefficient decrease with increasing $E_{\max }$.

6. The hardness of the Ni-Co alloy obtained by electrodeposition increases with increasing $E_{\max }$.

\section{References}

[1] L. Shia, C.F. Suna, P. Gaoa, F. Zhoua, W.M. Liu, Surf. Coat. Techn. 200, 4870 (2006)

[2] L. Wang, Y. Gao, Q. Xue, H. Liu, X. Tao, Appl. Surf. Sci. 242, 326 (2005)

[3] X.C. Li, Z.W. Li, Mater. Sci. Eng., A Struct. Mater. 65, 1 (2003)

[4] A.F. Zimmerman, G. Palumbo, K.T. Aust, U. Erb, Mater. Sci. Eng., A Struct. Mater. 328, 137 (2002)

[5] C.B. Wang, D.L. Wang, W.X. Chen, Y.Y. Wang, Wear 253, 563 (2002) 